\title{
"When words become unclear": unmasking ICT through visual methodologies in participatory ICT4D
}

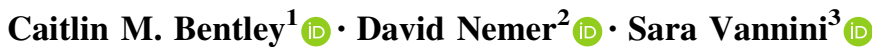

Received: 6 January 2017 / Accepted: 2 October 2017/Published online: 25 October 2017

(C) The Author(s) 2017. This article is an open access publication

\begin{abstract}
Across the globe, our work and social lives are increasingly integrated with Information and Communication Technologies (ICT), yet massive disparities in the values, uses and benefits of ICT exist. New methods are needed to shed light on unique and integrative concepts of ICT across cultures. This paper explores the use of visual methods to facilitate critical engagement with ICT-defined as situational awareness, reflexive ICT practice and power and control over ICT. This definition of critical ICT engagement is informed by a cultural identity lens, and intends to improve participatory methods in ICT for Development (ICT4D) and community technology design and application. Our notion of critical ICT engagement is developed through an analysis of three case studies, each employing visual methods to shed light on concepts and practices of ICT cross-culturally. This paper makes three contributions to the ICT4D literature. First, it establishes a cultural identity lens to chart out cultural differences between researchers and participants, and to develop
\end{abstract}

AIS Volume: Special issue: Cultural Diversity and Community Technology Design (CulTech)-volume to be allocated later.

Caitlin M. Bentley

cmbentley@ntu.edu.sg

David Nemer

david.nemer@uky.edu

Sara Vannini

vanninis@uw.edu

1 Singapore Internet Research Centre, Nanyang Technological University, 31 Nanyang Link, Singapore, Singapore

2 School of Information Science, University of Kentucky, Lexington, KY, USA

3 Department of Communications, University of Washington, Seattle, WA, USA situational awareness of ICT in context. Second, it defines the conceptual domain of reflexive ICT practice and establishes the key role of researchers in facilitating it. Third, it argues for the need to support participants to develop capacity to engage critically with ICT as a means to influence social and organizational structures. This paper offers a way for researchers and practitioners to engage with cultural issues in community-based research and design using visual methodologies.

Keywords ICT4D · Visual methods · Photography · Soft systems methodology $\cdot$ Participatory research . Action research

\section{Introduction}

The use of visual methods in social research is wellestablished (Collier and Collier 1986; Lunch and Lunch 2006; Clark-Ibáñez 2016). Such methods, like participatory photography or video, incorporate a visual element into the research process, usually by engaging participants to collect or construct photographs, pictures, or video, and then involving participants to analyze and interpret meaning (Pink 2004; Clark-Ibáñez 2016). For social researchers, visual methods can enrich their understanding of social contexts and problems, and they offer an inclusive manner to involve their participants fully (Bignante 2010). In some cases, visual methods empower participants to challenge customary assumptions and to change prevailing social and political structures (Young and Barrett 2001; Gomez and Vannini 2016). Despite this noticeable potential, visual methods have only recently been adopted in the area of Information and Communication Technologies for 
Development (ICT4D) (Vannini et al. 2015; Roberts 2016). ICT4D is a multi-discipline concerned with the application and impact of ICT for sustainable human development.

Simultaneously, there have been several sources of dissatisfaction in the state of ICT4D research and practice. Debates within the ICT4D community center on the '4D' aspect of the multi-discipline (Kleine and Unwin 2009; Heeks 2014; Chib 2015). Some scholars have argued against technological determinant views that emphasize access and adoption of ICT as the primary avenue to development (Kleine 2010; Toyama 2015). As a response, a growing number of ICT4D scholars have focused on the use of participatory methods to enable transformation from the ground up (Buskens and Webb 2009; Tacchi et al. 2009; Sadowsky 2012). Participatory ICT4D can have practical or emancipatory objectives, which attempt to empower and protect poor and marginalized populations. For instance, participatory design "is an axiomatic approach, and is characterized by the enactment of participation, both in terms of the researcher/designer and the participant/interlocutor. Typically, this type of activity is conducted in situ (in context, at the "grassroots") and is mutually negotiated for purposes of transformation, action, emancipation or development" (van Zyl 2014). Participatory ICT4D is often focused on a specific technology as a subject of design, or on a development objective enabled by ICT.

However, key theoretical insights regarding the nature of technology in society have not been adequately factored into participatory ICT4D methods. First, it is widely accepted that technology is not neutral (Kranzberg 1986; Leonardi 2012). This means that ICTs can hold different meanings and purposes for people across cultures. Second, research has uncovered unintended uses and consequences of technology that was not originally intended by design, but that has had both positive and negative impacts on the lives and communities of poor and marginalized people (van Reijswoud 2009; van der Boor et al. 2014; Hoque and Sorwar 2015). Third, recent reports have shown that the structural character of ICT surrounding access and use patterns have exacerbated social inequalities (Caribou Digital 2016; World Bank 2016). Fourth, a series of complex issues rooted in networked interaction are demonstrating increasing danger for everyone, such that privacy, safety and security are pervasive global concerns (Floridi 2016). Community members might not even use ICT, but improperly trust an organization that breaches their rights by mishandling their information online. Community members need to develop greater awareness and understanding of ICT, yet it is not clear how to integrate these insights into participatory ICT4D.

This study draws on three case studies to explore how critical ICT engagement may be enacted in participatory
ICT4D research in community settings. The three case studies were conducted separately by the authors. Each author reflects on the cultural issues that arose when researchers and participants held different meanings and purposes of ICT. The authors applied visual methods to draw out cultural issues, and to develop a greater awareness of ICT in context in different ways: by creating a photo book, by drawing rich pictures and through photo-elicitation. Explanations of these methods are offered in each case study. The case studies also highlight three different community contexts: Brazilian favela residents, staff members of a civil society organization in Southern Africa, and users of Mozambican community multi-media centers. Across the case studies, cultural tensions between the ways in which researchers and participants engage with ICT are identified. The authors reflect on how a cultural identity lens could support participants to engage more critically with ICT, such that individuals develop a situational awareness of ICT in context, apply reflexive ICT practices, and gain greater power and control over the use and design of ICT within their lives. The paper is organized as follows. We begin by problematizing two main research and practice orientations within participatory ICT4D. Here, we argue that ICT is conceptualized narrowly in terms of either its functionalities, as a companion, or as an interaction context. Next, we review the basis for applying visual methods to draw out other conceptualizations of ICT, to empower participants, and to increase contextualized understanding. To evaluate these claims, we articulate the conceptual domain of critical engagement with ICT in the context of underserved communities and the contributions of visual methods towards this aim across our three cases.

\section{Theoretical framework}

\subsection{Problematizing participatory methods in ICT4D}

\subsubsection{Parochial functionalism}

ICTs can be used to fill a variety of development needs. However, emphasizing the application of ICT to fulfill specific needs through the design or application of ICTs form a research and practice orientation that is parochially functionalist. Within this orientation, the dominant emphasis currently rests on the instrumental utility of ICTs, which is problematic for two reasons. First is the emphasis on one tool, system, or need over a broader view of ICT in society. We illustrate this limitation with an example drawn from participatory action research on developing health information systems in ICT4D (Mosse and Byrne 2010; Sahay and Lewis 2010; Nguyen and Braa 2016). 
Such studies have benefited from social-embedded, actionoriented approaches by directly involving the people who use the system to contribute towards its specific functionalities in culturally appropriate ways. For example, Nguyen and Braa (2016, pp. 1) stated their aim as "assembling multiple socio-technical components and transforming them into a larger health information infrastructure", exemplifying that the main purpose is to establish the system first and foremost. Such an approach can marginalize ICTs that are already integrated or embedded in community and institutional contexts. In other words, this approach can focus attention on specific functional needs above and beyond the contextualized impact of ICT. Participants thus gain expertise to engage with ICT per its role within the project or system. However, Mosse and Byrne (2010) have argued that collective identities surrounding technology are generated through more than engagement only with health information systems implementations. It is beneficial for participants to understand their own relationships with technology, in addition to their role specific purposes.

The second reason parochial functionalism is problematic is more structural. How successful might a functionalist approach be in the context of a small rural community with a distinct need? Some argue that hardware and software is increasingly adaptable even to the most difficult of circumstances, due in part to technological innovation (Kraemer et al. 2009; Donner and Escobari 2010; van der Boor et al. 2014). Alternatively, Okon (2014) argues that technologies will never have a singular purpose, which is even more pronounced in the rural Nigerian communities within which her research took place. She suggested a context-driven approach to enable communities to define the parameters of use and meaning of ICT themselves. However, small rural communities may have limited scope to design new technologies on their own. For those communities that seek to address very simple, stable needs that are not likely to change, there may be no problems with parochial functionalism. But for communities and institutions that have complex, opaque, unique or changing needs, functionalist approaches may have limited effectiveness to address long-term ICT needs responsively. In either case, a long-term or community-based purview is required to evaluate these aspects.

Parochial functionalism runs the risk of promoting ICT in a way that is overly focused on short-term gains, and actors may lose sight of long-term development concerns, as well as the role of ICT in the broader sphere. Heeks (2002) identified a similar tendency through his analysis of failure of information systems projects in developing countries arguing that projects tend to ignore relationships or systems and actors with the broader ICT context, and end up putting failure down to project-related factors.
Heeks (2002) suggestion was to focus on improvisation as a means to reduce design-reality gaps by understanding ICT realities as they are, but this also requires gaining skills to do something with this knowledge. The challenge remains to find a balance between short-term practical needs that ICT can address, and the more empowering skill set that is needed to critically engage with ICT in the longterm.

\subsubsection{Emancipatory logic}

The second problematic within participatory methods in ICT4D concerns emancipatory logic. Emancipatory principles espoused by ICT4D scholars are frequently based on notions of freedom, empowerment, transformation, agency, justice and voice (Buskens and Webb 2009; Tacchi et al. 2009; Kleine 2010). However, ICTs are not normatively principled, and are often conceived as a means to change emancipatory conditions. For instance, a significant body of participatory research was outlined by Buskens and Webb (2009). Their book had three emancipatory themes: (1) agentic use, (2) critical voice, and (3) personal and social transformation. Agentic use refers to developing an awareness of technology in practice. Whereas, critical voice and transformation imply that people should use technology ways to change their own position, and to influence social structures. The book signifies a turn towards an emancipatory logic. It presents a welcomed and necessary transition in ICT4D in which, by addressing longer-term development concerns, runs in opposition to parochial functionalism.

However, working towards some emancipatory principles does not always translate into power and control over ICT itself. Orlikowski (2000) has argued that ICT is entangled in its context, and the same technologies can be enacted by actors considerably differently. Some actors may enact technology in ways that do nothing to change their practices and position, whilst others may go so far as to improvise design improvements that transform their environment for themselves and others. However, in contrast to Buskens and Webb's (2009) notion of agentic use, participants may be unconscious of their technological enactments according to this perspective. As such, participants may gain the skills to apply specific ICT in beneficial ways, without gaining skills to evaluate new ones, or to engage with the wider influence of technology on their lives and society. Participatory design scholars have likewise remarked that participants tend to have difficulty imagining how ICT will operate before interacting with it, and grow disappointed when design outputs do not meet their expectations (Maunder et al. 2007; Doerflinger et al. 2013). Similarly, for methodologies that engage participants to use technology instead of designing technology, 
such as such as participatory video, ICT can become too invisible, detaching the skills and resources needed to use and maintain ICT (Vallauri 2015). Rather infrequently within participatory ICT4D research, are participants encouraged to identify and challenge political and social inequalities that structure ICT specifically. Our notion of an ICT-focused dimension of emancipation stresses that ICT is also based in power structures, they are also culturally imbued and embedded in social relations (Zheng and Stahl 2011)

As such, there is a disjoint between emancipatory logic, which emphasizes freedom, protection and empowerment, and the structural character of ICT which can be disempowering, harmful, symbolic, or enacted as neutral. Whilst participatory methodologies, such as action research, participatory design and participatory video have been increasingly practiced in ICT4D, these methodologies do not specifically target critical engagement with ICT in and of themselves. However, there has not been much research into what critical ICT engagement may entail. The next section outlines our approach.

\subsection{Critical ICT engagement: a cultural identity lens}

To address the above problems in participatory ICT4D research, we suggest a cultural identity lens may appropriately frame critical ICT engagement. Thus, this article aligns with a host of scholars who have called for more culturally sensitive approaches to ICT4D (Tedre et al. 2005; Irani et al. 2010; Brunello 2015). According to Hall (1996, pp. 4), “[cultural] identities are never unified, and in late modern times, increasingly fragmented and fractured; never singular, but multiply constructed across different, often intersecting and antagonistic, discourses, practices and positions". From this perspective, understanding culture involves drawing out several identity factors such as gender, class, race, ethnicity, kinship, and power in a situated manner (Hakken and Maté 2014). However, as Hakken and Maté (2014) have argued, within participatory ICT4D methods, and Participatory Design (PD) in particular, culture has often been conceived as a single and unified entity with ontological status. We explore whether Hall's (1996) critical notion of cultural identities, along with Hakken and Maté's (2014) focus on bringing identity phenomena together provides a more robust framing for critical ICT engagement.

A cultural identity lens contends that "culture is negotiated, malleable, and intertwined with power relationships" (Merritt and Stolterman 2012, pp. 74). This perspective implies that perceiving, using and designing ICT generate cultural identities, which may affect power and control over ICT in context. Participatory methods have often been perceived as a means to address power inequalities within technology design in developing countries (Dearden and Rizvi 2015). However, as Merritt and Stolterman (2012) remarked, such methods sought to balance power inequities within one (predominately Western) culture, which poses a problem when design groups and users belong to different cultural contexts. Furthermore, ICT4D participatory projects may be conceptualized and initiated by researchers from a different cultural background than where the project is implemented. A cultural identity lens unpacks potential differences and urges researchers and participants to develop a situational awareness of ICT and community dynamics together in context, by considering the interaction effects of both the researcher and participants' cultural identities.

Moreover, the constructive, practice-based qualities of a cultural identity lens infer that there are emergent aspects of critical ICT engagement that researchers must develop a consciousness of. Participants will also have important contributions to make regarding the use and design of ICT within their lives, and new emancipatory principles may emerge as participants learn and experiment with ICT (or as they hit roadblocks). By focusing on culture as reflexive practice in participatory methods, we hope to develop a more inclusive and democratic approach to disrupt power laden notions of technologies (Irani et al. 2010). In sum, our analysis adopts a cultural identity lens which centers critical ICT engagement on the following: (1) situational awareness of the role of ICT in context, (2) reflexivity in ICT practice, and (3) power and control over either the use or design of ICT. However, we have not yet treated how deep-seated cultural issues related to class, gender, power and position may come to the surface in participatory methods. The next section focuses on visual methods for this purpose.

\subsubsection{Enabling critical ICT engagement through visual methodologies}

We explore the potential for visual methodologies to address a need to enable critical ICT engagement within participatory research and practice. Visual methods have many established benefits, which we argue are fit to this task. We define visual methodologies to mean research methods that incorporate a visual element to collect data or as an intervention strategy (Pink 2004). A visual element can be a photograph, computer or hand-drawn picture, video, or other visual media. These different mediums, however, are commonly associated to specific methodologies that have distinct origins and purposes. We take a nondiscriminatory position towards visual methodologies in favor of exploring the benefits of visual elements, in their broadest sense, for critical ICT engagement. 
For example, there are many approaches to participatory photography, yet there are some benefits stemming from the use of visual elements that cut across participatory photography methods and outcomes. To illustrate, research that has focused on migrant populations has applied participatory photography in the context of participatory action research (Kwok and $\mathrm{Ku} 2008$ ), focus groups (Holgate et al. 2012) and facilitated photo assignments and discussion (Rhodes et al. 2009). In these studies, participatory photography was used for different reasons: to solve urban design problems (Kwok and $\mathrm{Ku} 2008$ ), to generate insight into the lives and cultural identities of Kurdish workers in London (Holgate et al. 2012), and to understand risky behavior of Hispanic men in the US, linking alcohol and sexual violence (Rhodes et al. 2009). However, a key component across all three studies, was that visual elements helped to articulate cultural identities, creating a bridge between researchers, participants and community members from different cultural backgrounds. Particularly within Holgate et al. (2012) and Kwok and Ku's (2008) studies, another key component was the use of visual elements to record snapshots of daily life, to build understandings of living experiences, and how people cope with their environments. The use of photographs to tell stories of practices and experiences could help to develop situational awareness for critical ICT engagement, especially when many cultural factors are difficult to verbalize. Likewise, these studies demonstrated that visual elements can facilitate reflexivity along both psycho-social and interpersonal dimensions.

Another benefit of visual methods relevant to critical ICT engagement is inclusivity. Visual methods enable even the most-marginalized of populations to formulate their thoughts and explain their ideas to researchers. The earliest application of visual methods was by Collier and Collier (1986), as he worked with pre-literate indigenous populations to understand their understanding of certain topics even when he had little experience in their way of thinking and doing. Likewise, Yefimova et al. (2015) argued that visual methods are not linguistically dependent, and are easily adapted to any context or population. Snapping photos, or taking a paint-brush to paper has been rapid to support people of various ages and abilities to participate (Young and Barrett 2001; Clark-Ibáñez 2016). In contrast, as remarked by Bignante (2010) sometimes researchers may confront completely different outcomes than their initial intention, as there are no set of structured questions or formula to follow. However, this may also be a benefit as participants may feel more freedom to explore their own ideas rather than to please the researcher (Vannini et al. 2015).

Lastly, the empowering potential of visual methods may also help researchers and participants to mediate power differences key to critical ICT engagement. According to Freire and Giroux (1985), photos help to create a material representation that supports reflection such that participants can compare their own thoughts on the matter in order to identify ideas for action. Similarly, Checkland's (2000) soft systems methodology focuses on rich picture drawing as a means to work through a problem situation and to build contextualized solutions. However, Pink's (2004) discussion of visual ethnography highlights that visual methods are not merely visual. Visual methods are often situated within other research methods, which may limit empowerment potential if researchers do not strive to support empowerment goals. Visual elements may also be disempowering if researchers breach ethical commitments towards them, or if they cause unintended harm.

\section{Case studies}

This article explores visual methods for critical ICT engagement through three case studies that were investigated separately by the three authors. Each case study begins with a short introduction that identifies the researcher and project. The cases are then written by the author in the first person. These case studies were part of larger research initiatives that utilized different methodologies responding to their research objectives. The authors therefore contextualize their motivation and specific approach to the research briefly. Variation across case studies provides ground to investigate the application of visual methods broadly. However, each case study analyzes the role of visual methods for critical ICT engagement by focusing first on the enacted visual methods, which are described in Sect. 3.1.1, 3.2.1 and 3.3.1. Second, they reflect on the effects of the methods to support participants to critically engage with ICT. Each section ends with a reflexive discussion of the methods in Sect. 3.1.2, 3.2.2 and 3.3.2.

\subsection{Favela digital, Brazil}

The first case study centers on the use of visual methods to illustrate ICT practice in order to reduce social geographic divisions. The case study is based on Nemer's (2015b) extensive ethnography within the favelas located in Vitoria, Brazil. ${ }^{1}$ Upper-class Brazilians have stigmatized favela residents as favelados: criminals, resource poor, ignorant, and useless members of society. However, as observed by Nemer (2015a), favelas were highly technological ecologies, where the people were tech savvy and used digital technology to overcome their limitations. Due to the social

\footnotetext{
${ }^{1}$ For more information about the favelas and research context see Nemer (2015b).
} 
and power dynamics in Brazil, most favela residents accepted their life conditions and the stigma attached to them. Thus, there was a need to create awareness both inside and outside the favelas of the unique ways that ICTs have been appropriated (Nemer 2016). The value of visual methods emerged when Nemer's (2015b) ethnographic photos sparked people's interest during focus groups with favela residents in 2013. The following two sections outline his approach and the outcomes attributable to the visual elements in his process.

\subsubsection{Application}

I decided to create a photograph book as a tool for critical engagement, since the scenes that I encountered were rich and illustrative of the unique reality of the favelas. The book was entitled Favela Digital: The Other Side of Technology. It contained 60 photos and short texts, aiming to highlight social issues of technology use in favelas and in society (see Nemer 2013). An academic book based on heavy text was not appropriate to communicate with Brazilians, rich or poor. Illiteracy is quite high among favela residents due to the inefficient public education available there, and Brazilian upper class do not read frequently. About $50 \%$ of Brazilians read at least 1 book a year, which is considered a very low rate when compared to other countries (Mello 2016). The idea came to me, after I used photos to spur discussions in focus group sessions and confirmed that photos were accessible and engaging to both populations. Paula, ${ }^{2}$ favela resident female and 26 years old, raised a set of intriguing questions during a focus group held in June 2013:

Wow! This is incredible! [looking at a photo of a mesh network at favela São Benedito] How did they [residents of São Benedito] manage to build such thing? How do they have such knowledge? How do they maintain that network?

I also happened to meet employees of an NGO who were undergoing journalism training. The NGO, called Varal Communication Agency, was creating a newspaper and radio station for favela residents at the time. The employees were also favelas residents, and required training and practice. We decided to work together on the photography book project.

We walked around the favelas for approximately 1 month. We looked for scenes that captured the nuanced ways that the residents were using technology (see Fig. 1).

Whilst we had this theme in mind, we often engaged in discussions during the favela tours. In each scene or photo

\footnotetext{
2 The quotes presented in this case are from favela residents who had their names changed to preserve their anonymity.
}

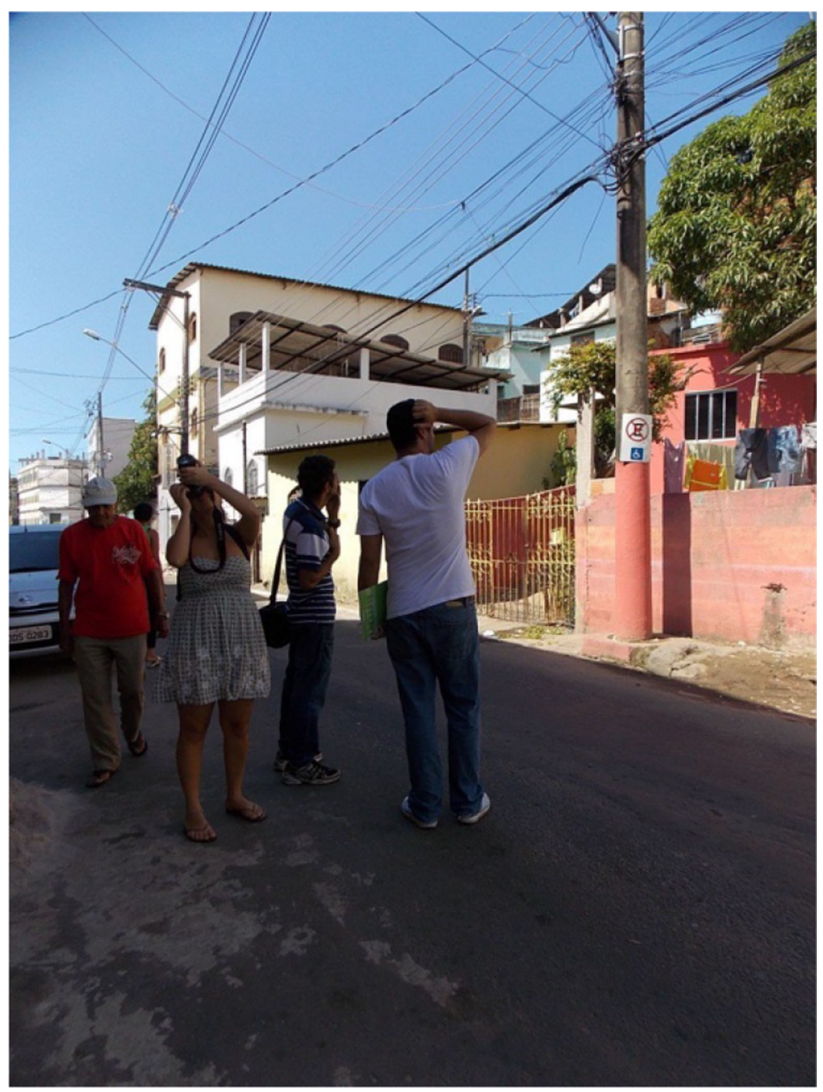

Fig. 1 Nemer and Varal's photographers in action

taken we reflected upon the meaning of the photo, technology, and the people. This enabled me to understand our differences in viewing the favela realities and enabled them to express their thoughts on which were the most representative photos of their favelas. This way, they were thinking about the photos and gaining a better understanding of the potential of favela residents. As one of the photographers Robson, male and 28 years old explained:

Look at these power supply units (PSUs) [as we enter a Telecenter's storage room]. I can't believe they recycle them right here in Itarare [one of the favelas studied]. They [Telecenters] need a large supply of PSUs because the infrastructure in the favelas is very faulty and unreliable, it fries the PSUs all the time [...] PSUs are what keep the Telecenters' computers safe from these large voltage spikes. Hopefully this photo will draw attention to the lack of investments in our infrastructure.

The photos also amplified the photographers' frustration and resentment due to the neglect with the favela's situation, as protested by Bruna, female and 19 years old:

This is awful [looking at a photo of a pile of electronic waste that go accumulated in favela Bairro da 
Penha]. They dump Vitoria's e-waste here at our territory because they think we are not worthy or we won't complain about it. Why don't they dump this at Praia do Canto [rich neighborhood in Vitória]? ... because they know they will get in trouble- but that's fine, I will take a photo of this situation and put it in the book, people will finally see our reality and hopefully do something about it.

The photos therefore showed innovative and creative ways of using ICTs, but also represented greater meaning of ICTs in the lives and environments of favela residents.

We then selected photos for the book that best represented these diverse meanings over 3 meetings in September 2013 at the NGO Varal, as shown in Fig. 2. After selecting the photos, I attributed text to demonstrate the photos' theme-the text was not collected at the same time of the photo. Passages were collected during fieldwork which started prior to the book project, including quotes from residents and scholars that had influenced me. The photographers had an opportunity to comment on the

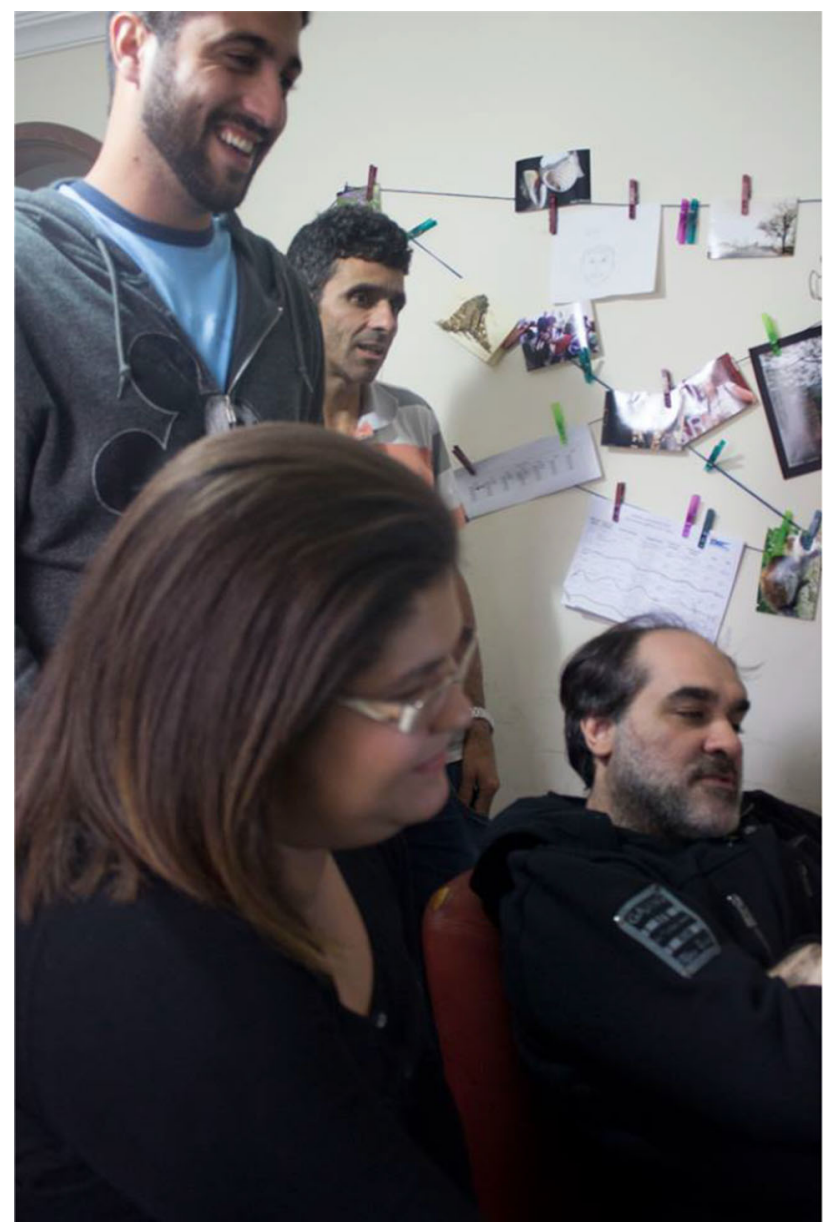

Fig. 2 Nemer and Varal's photographers selecting the photos for the book representativeness and fit of the quotations and photos, and all agreed.

\subsubsection{Outcomes}

Although I am Brazilian, my cultural identity is significantly different from the favela residents. I begin by explaining how creating the photo book with favela residents helped me to negotiate my cultural identity whilst also constructing situational awareness of ICT in context. I then turn to the influence of the photo book to support the residents to critically engage with ICT themselves.

I lived in my family residence during the research, which was just a 20-min walk away from Itararé, the closest favela to my home. My home is located in an upperclass neighborhood, and I studied in private schools in Brazil that followed western educational models. Despite my proximity to the favela, I was unfamiliar with the area. Yet, I was surrounded and influenced by the local practices and situated knowledge, such as playing pelada (a specific Brazilian kind of pickup soccer) in the streets, going to rehearsals of Samba schools, and participating in Capoeira circles (a Brazilian martial art that combines elements of dance, acrobatics, and music, which was developed by Africans in Brazil). I was aware of the differences of power and status that my background would bring: male and upper class. However, in order to alleviate the barriers that such differences may have caused, I approached participants as conversational partners (Rubin and Rubin 2011). Prior to developing any awareness of ICT, my approach first centered on listening to participants with an open heart and mind, and to truly consider what they expressed. My motivation was not to judge them, but rather to understand them. Such an attitude surpasses any notion of critical ICT engagement, because the researcher is actively sensing and thinking about what is being expressed and is deeply engaged beyond the topic of study.

Being inside the favela, at first, seemed to be an issue for different groups of people. My family was worried and not pleased with the timing of my fieldwork (due to the intense drug war that was happening then), some of my friends thought I was insane for risking my life "to teach poor people how to use computers", and some participants did not want an outsider doing research within the favelas. The word research stirred up silence, conjured up bad memories and caused distrust. Favela residents mentioned being approached by previous researchers as guinea pigs, which implicated an excess of classism, rude questions, and condescending power. Residents viewed that research, instead of benefitting them, classified and represented their life experiences according to the researcher's perspective. The favela residents did not identify with how their stories were being told and exploited, which has consequences. 
When culture is a set of practices, representations are influential forces that shape how people are treated (Hall 1997).

Hence, the book project Favela Digital was deployed in order to address this issue of misrepresentation, in which favela residents were actively involved in the process and had a voice to determine the photos and text that represented them best. The book embodied a responsibility to "resist domestication" by using the resources, skills, and privileges available to provide a fair and empowering account of favela residents, whose stories are retrained and out of reach (Madison 2011). Telling the untold side of the story through the lenses of the marginalized, who have been suffering the consequences of marginalization and exploitation, promoted their recognition as human beings who deserve respect and recognition for their values, and beliefs. However, it was not clear whether my vision for the book would be accepted and experienced by the residents in the same way. Organizing focus groups was a way to evaluate how the favela residents viewed the book.

The book was launched on October 2, 2013. On October 5 and 7, I organized focus groups at the Telecentres within the Itararé and São Benedito favelas. I gave each participant a free copy of the book as a thank you gift. During these meetings, 6 favela residents, who were frequent users of these Telecenters, went through the book and told me what their thoughts were:

Finally, people will see that favelas go beyond that limited image of violence and drug trafficking. [...] People we'll see that we are constantly engaging with technology in critical ways. [...] because we don't have access to resources, we have to tinker all the time- we can't afford to buy new computers, we have to maintain what we have... and this is the future. We are also helping society by reducing the amount of e-waste in the world (Marcos, male and 23 years old).

Some were impressed by their own capabilities, as Marcos described how being unable to afford computers has caused some residents to learn how to make effective use of available resources. For others, the revaluing of ICTs and associated capabilities changed their opinions of themselves. They began to see themselves differently than the way the upper classes persistently tried to label them. Lícia, female and 17 years old stated:

Look at how we are using social media... we are using it to escape from the drug war, prejudice, racism... we are spreading business, knowledge, love, and care through technology. [...] We are showing how it's done. They [upper classes] have no rights to judge us, we are the future!
As Custódio (2014) agrees, in a context where the urban poor are constantly criminalized or stigmatized, the book's images can potentially create a sense of empowerment and pride among favela dwellers. The short texts both in English and Portuguese also create an opportunity for favela dwellers to read, evaluate, and use the book as a starting point for their own discussions about their own uses of digital media. Custódio (2014) believes that Favela Digital would be an important addition to the curriculum of public schools in Brazil (where most urban poor populations study), for example. However, there is still a need to investigate how this might be done, and to what end. From my own personal experience coming to understand ICT through the eyes of the residents, there seems to be an opportunity to use these visual materials to communicate with the Brazilian upper class to reduce discrimination. Most of the residents believed that the book would change perceptions of them. It would be beneficial to conduct further research to evaluate these beliefs.

\subsection{Gender Links, southern Africa}

The second case study concentrated on the role of ICT in donor-civil society organization relations. This paper focuses on Gender Links, a regional civil society organization. In 2016, Gender Links employed 48 staff and had a budget of over 3 million Euros. The organization is best known for spearheading the Southern African Development Community Gender Protocol Alliance, and has developed award winning programs related to their local government and media influence (Gender Links 2010, 2016). Gender Links operates in 15 countries and seeks to work towards gender equality at local citizenship levels, through local government and media institutional change, and to influence state government policy. Academic discourse positions civil society organizations, such as Gender Links, as key sources of empowerment and support for poor and marginalized populations (Bebbington et al. 2008; Lewis and Kanji 2009; Van Rooy 2009). However, a growing problem relates to the approaches that organizations and their donors use to learn about practice, and the ways in which participants contribute to these learning approaches (Wallace and Chapman 1999; Ebrahim 2003; Balboa 2014). At the time of research, Gender Links had 17 major donors that all required Gender Links to report on its progress in specific formats. Ideally, these reports are meant to help practitioners, managers and donors learn about what is working well, and to respond to the needs of their beneficiaries effectively. Yet, as Balboa (2014) has argued, organizations like Gender Links are finding it increasingly challenging to balance competing requirements and learning objectives across diverse stakeholders and international contexts. Bentley's research 
initially sought to explore the design and use of ICT to facilitate learning and knowledge sharing across beneficiary, CSO and donor contexts more harmoniously. However, as outlined below, research conditions changed for reasons beyond her control. Ultimately, the fieldwork for this case study was conducted in three of the 15 countries where Gender Links operates: South Africa, Mozambique and Swaziland. Further details are given in Bentley (2017).

\subsubsection{Application}

I worked as a participant observer at Gender Links headquarters, Johannesburg, at the Mozambique satellite office (one out of 10 satellite offices), and at a training event in Swaziland over the course of 6 months in 2012-2013. During this time, I contributed actively to all core programs by updating the website, editing publications, interviewing beneficiaries and conducting evaluation activities. During the research, I also conducted two types of interviews with 17 staff members total: the CEO, two Regional Directors, two Country Managers, one Editor, four Country Officers, three Headquarters staff, and three Program Managers. Country staff were from 8 different countries, and participated in interviews while at headquarters for a workshop. First, participants could choose to participate in modeling interviews, which were designed to guide them through drawing rich pictures about their learning and accountability processes. About half of the staff interviewed chose to participate in semi-structured interviews instead due to time constraints. However, I focus on the modeling interviews in this paper because these contained visual elements.

Rich pictures were defined according to Checkland's (2000) Soft Systems Methodology (SSM). However, the rich pictures are but one part of an SSM process. According to Checkland and Poulter (2006), there are three main stages to carrying out a soft systems methodology. The first is a finding out stage, which consists of identifying relevant worldviews, or perspectives of problem situations. My time working as a participant observer was particularly helpful to observe difficulties in the ways that ICT was used to share knowledge between the various stakeholders of the organization. I drew on this experience to guide the participants through the modeling process. The second stage, the modeling stage, is focused on building models through the construction of rich pictures that help to create and establish representations of existing relationships between people, organizations, activities, and objects. The last stage uses the models as a starting point to discuss the relationships identified within the rich pictures. Discussion is used to draw out the normative claims of what the participants judge ought to be, which helps to plan feasible solutions to problems.
I intended to follow SSM to facilitate identifying and discussing the most pressing learning problems, and to investigate how ICT could contribute to resolving these problems through action research afterwards. I planned to carry out the SSM analysis in workshops with groups of staff together, because conducting such discussions in groups permits researchers to observe tensions or easily accepted views (Morgan 1996), and to support actionplanning within the group. However, when I arranged a workshop with program managers, an important campaign had started and staff were busy. I needed the CEO's direct support, but she was also occupied. With limited time to complete the research, I changed to a strategy that did not require all staff to meet. This is why I completed the modeling interviews individually. I interviewed a crosssection of staff at Gender Links, totaling nine modeling interviews (five junior and four senior staff, five men and four women). Interviewing a majority of staff from both headquarters and country offices, who differed by seniority provided a representative sample of the organization.

During interviews, participants were asked to draw pictures of their own learning and accountability processes. I focus only on learning in this case to simplify matters for the reader. Engaging with the participants to build models ideally leads to hypothetical descriptions, which often revealed underlying mechanisms of their realities (Blaikie 2010). Building models also enables participants and researchers to transform pictures into textual definitions of goals, values, and activity systems, and the relationships between these. Once participants had finished drawing, we discussed different aspects of their pictures to understand why it was the way it was, and how they saw the role of ICT in the picture. They were also asked to evaluate their process for efficiency, effectiveness and ethics.

Supporting participants to draw their own pictures required a great deal of support. Not a single participant started drawing a picture without first seeking clarification on what was expected. I showed the same scaffolds of different types of pictures, and I gave standard questions to help them reflect. These scaffolds demonstrated a range of approaches to the task, and participants then felt confident to continue on their own. There were two main corresponding features across learning diagrams. The first was that pictures reflected their roles in the organization, such that junior staff (Country and Headquarters staff) drew pictures of their individual learning style (five out of five junior staff), whilst managers drew pictures of programmatic learning processes (three out of four senior staff). Second, across all diagrams, participants drew pictures that showed stakeholders connected across distances, primarily due to ICT, yet it was not until the discussion started that participants remembered to indicate the role of ICT in their pictures. Details are discussed further below. 


\subsubsection{Outcomes}

Picture drawing influenced the participants' perception of the research, and helped us both to develop a greater awareness of our divergent concepts of ICT. From the modeling interviews, it was apparent that staff did not see any problems with the ways in which they used ICTs to learn from their beneficiaries, about organizational practice or to share knowledge with their donors, contrary to dominant discourses. However, I had observed staff overwhelmed at work, struggling to balance heavy workloads, and to respond effectively to their growing numbers of diverse beneficiaries. One officer drew a picture of himself atop an anvil with a hammer positioned over his head to convey the amount of pressure he felt daily. All other staff reflected on how the stressful work environment affected the quality of work, and their relationships with beneficiaries. Yet, staff did not view ICT as a means to resolve these problems. There was a disjoint between my perspective and theirs, as I could see many opportunities to use ICT to reduce workload pressure. Yet, I lacked the power and position to convince staff to pursue these options amidst their overwhelming schedules. Having the rich pictures to refer to during our discussions was important for establishing these differences, and to influence staff perceptions of these matters.

Sultana (2007) cautions that researchers, such as myself, may automatically have a dominating position because I am a white Canadian, who was studying at a prominent UK institution. However, at Gender Links, I was often introduced as an intern, and interns were considered the least experienced within the organization hierarchy. Most staff at Gender Links, especially those in senior positions, were highly educated and experienced, and had been recruited to work at headquarters from across the region. I was also initially perceived as a passive researcher, as it seemed that staff believed the donor had sent me to learn about how well they were using ICTs. Becoming a participant observer helped me to gain trust and an insider status within the research context, and to understand the participants' daily struggles. Yet, my position as an ICT researcher led me to view all organizational practices and problems amenable to ICT intervention, whereas the participants tended to view ICTs as rigid or unchangeable structures of the organization. Senior managers mandated staff ICT use, outlining specific rules and procedures to follow. I had assumed that staff had some power and control over their ICT use due to their vigorous work attitudes, and proactive behavior. It was not until I saw picture representations of the hierarchy and an absence of ICT that I started to draw out these differences.

The rich pictures also provided a means to debate with the participants about their perceptions, and in some cases, participants began to see some contradictions in their ICT practice. To illustrate, Fig. 3 depicts one manager's learning diagram, within which headquarters, country offices, partners and donors are geographically separated. Lines connecting stakeholders represented communication channels that existed between them. Within the two parts of the diagram, the centrality of headquarters to determine the concept and strategic direction of the program is apparent. The country office is subsumed under headquarters, and its role is mainly to be the eyes and ears of headquarters. There was no ICT depicted originally. Only after asking her directly about ICT, the manager began to label the lines by the type of ICT that is used within the channel "how do you draw a phone? Because this line I wanted it to be a phone. I guess, I can put e-mails too". She then discussed at length that the ICT needed to serve as eyes and ears on the ground was quite different from the ICT needed to compile monitoring and evaluation evidence for donors. She spoke of facilitators and beneficiaries that mainly had access to mobiles or fax machines, whilst she was accustomed to working online at headquarters through email, yet there was no differentiation in the picture to show these distinctions. She also admitted being aware of connectivity differences, but did not fully understand the impact poor connectivity had on her staff across countries, "In the countries like Zambia I haven't really tracked".

However, when the manager evaluated her process, her response was emblematic of virtually all the other interviewees. She said, "I would say it's very effective because we try to bring people together, all these people to share knowledge, to share their challenges, you know, and strategize on how they can take the work forward". Participants were generally accepting of ICT differences as a matter of fact, even if these differences significantly disadvantaged working patterns, and learning from beneficiaries. Participants chose to focus on technical, cultural

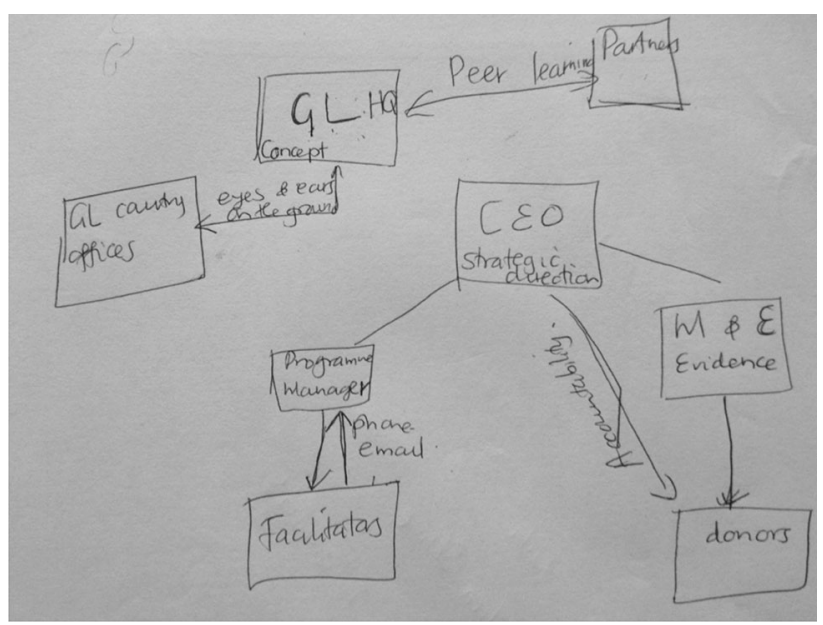

Fig. 3 A program manager's learning process diagram 
and interpersonal conflicts within the organization, and did not see ICTs as a means to resolve the learning issues I had observed. Whilst the picture drawing enabled participants to identify and explain the key roles of ICT in context, which were often invisible to them at first, they did not exhibit a desire to reflexively change ICT practice. I needed to ask targeted follow-up questions relating to specific practices that I had observed in order to shed light on the contradictory aspects of their evaluations and to question why they did not see ICT as a means to address the problems identified. There were two main reasons for this. First, a workshop would have been much more effective in challenging poor evaluations of learning problems and solutions. Second, the hierarchical structure of the organization necessitated a different approach (than a soft systems methodology) to engaging with ICT due to the limited responsibilities interviewees had to act as problem solvers and a lack of power to influence organizational ICT. The rich picture drawing activity shed light on these issues of power and control over ICT, and helped me to revise my own understanding of the situation. The pictures also facilitated participants to reflect on these aspects.

\subsection{Community Multimedia Centers, Mozambique}

The third case study focuses on using photos as part of an interview process (a method called photo-elicitation) to understand local stakeholders' conceptualizations of ICTs and of public ICT access facilities, called Community Multimedia Centers (CMCs), in Mozambique. Elicited photos were used to engage local stakeholders in a dialogue with funding institutions. Beliefs, ideas and practices of how CMCs and ICTs could respond to the needs of the local population were compared and discussed. Photoelicitation was chosen in this case for two main reasons: first, to include people with different levels of education and societal positions in an interview process, potentially leading to empowerment gains. Second, to enable the researcher to understand the context quickly. The case study was conducted by Vannini as part of a larger research project in collaboration with: the Universidade Eduardo Mondlane, Maputo, Mozambique; the University of Lugano, Switzerland; the Swiss National Science Foundation; and the Swiss Development and Cooperation Agency. The field work for the project was conducted in two phases, a photo-elicitation phase between March and April, 2011, and a focus group phase between April and May 2012. Each phase involved one CMC in each of the 10 regions of Mozambique. During Phase 2 the directors of the $10 \mathrm{CMCs}$ were involved in discussing results and visual content generated in the first phase, and that led to a session of codesign of improvement projects for their CMCs. See Vannini et al. (2015) for full details about this project.

\subsubsection{Application}

During the photo-elicitation phase, 48 staff members and 53 users of $10 \mathrm{CMCs}$ were asked to take pictures and participate in interviews. I provided participants with a compact digital camera and asked them to take photos based on three prompts: (1) what they liked the most of their CMC; (2) what they would improve; and (3) what the venues represented within their lives. These prompts were meant to elicit their values and practices connected to $\mathrm{CMCs}$, and to understand their ideas about what CMCs should and should not be. The prompts and interview questions were also crafted to be easily understood despite education level, ICT skills, and familiarity with visual expression. Furthermore, questions were open-ended and participants were free to portray anything. After taking the photos, participants would come back and explain to me their photo choices in an interview. I then analyzed the data they generated in this phase both at the level of the image (content analysis of their photos) and at the level of the text (content analysis of their interviews).

The second phase consisted of two focus groups with the directors of the CMCs involved in the first phase. Within the first focus group participants discussed the photos generated in the first phase of the study and gave their interpretations. Following this, I presented my content analysis of the interviews and asked the directors for feedback. The discussions around the data led to a second focus group, where directors co-designed small projects for the improvement of their own CMCs that were grounded in the ideas and practices of their communities.

In contrast to my prior research, which analyzed interviews without photo prompts (see Rega et al. 2013), the use of visual material put participants at ease with bringing up different ideas during interviews. In many cases, participants did not take photos directly related to ICTs used in the CMCs. Instead, participants brought back photos of the CMC surroundings. Participants were relating to the $\mathrm{CMC}$ as a community place. During focus groups, the photos stimulated vivid discussions about the values and meanings participants attached to ICTs in this regard. Discussing photos depicting the role of ICTs and CMCs within their communities led to concrete ideas for improvement, which were grounded in community-generated data.

Despite these benefits, we confronted several challenges related to the differences in visual literacies and camera use skills between the researchers and participants. All participants knew how to take photos using a camera, as well as the concept of taking pictures. However, some had only used cameras from their cell phones and others had never used a digital camera equipped with zoom, flash and different shooting modalities. Some participants had trouble while using the zoom or flash, and were not accustomed to 
selecting a shooting modality. The researchers reflected on whether participatory photography was a suitable method within Mozambican communities. However, we assumed that any camera would do instead of considering which cameras and features participants were already familiar with. Moreover, some participants had difficulty translating images into abstract concepts, such as by using or creating metaphors in order to point out issues or ideas that could not be concretely seen. This visual rhetoric issue was also underestimated in the projects' preparation, in which we assumed that the visual language was rather universal than either personally or culturally influenced. As I did not have the resources to address visual literacy issues within the realm of the project, I allowed my analysis to be guided by the participants' diverse approaches to conceptualize the imagery, as gauged in their interviews.

\subsubsection{Outcomes}

In this research, several layers of cultural distance separated me from the communities I was working with. First, my research was part of a bigger joint research project between my University in Switzerland, and the only public University of Mozambique. The research team, consisting of myself, three professors, a post-doctoral researcher and another $\mathrm{PhD}$ student, traveled together to different locations, spending 3 or 4 days in each community. We wanted to be flexible and responsive to the communities' contextual peculiarities, but at times we could not be as responsive as we would have liked due to the time constraints, and the challenges of working on team-based research. Second, our team was multi-cultural and multi-racial: half of us were white Italians, and half of us were black Mozambicans. Overall, we were as many women as men. As a foreign white Italian, being European but not Portuguese, at least did not charge me directly with the colonizers' legacy. My association to the Universidade Eduardo Mondlane was also perceived in a positive light. Based on personal experience over 7 months in Mozambique, these aspects generally contributed a positive bias within the research. Such a positive bias should not be taken lightly as Dell et al.'s (2012) experiment showed how a marginalized population was five times more likely to prefer technological artifacts simply because they were given by foreign researchers. However, Mozambique has 17 different groups of local languages and many ethnic groups. In some cases, my colleague from Mozambique was entrusted with less information than I was, as his Southern origin, education level and socio-economic status were perceived as conflicting, almost rival to the ones of the community. In other cases, the opposite happened. These situated cultural identities were both blessings and a curse, and were not always easy to predict. In general, I did not encounter major difficulties in any of the 10 research sites. However, I often noticed that my participants were trying to please me, which put me in a more powerful position.

This is one of the reasons why I chose to employ a visual methodology in the first place, as photographs, a shortcut to the soul, can help create stronger relationships between researchers and participants in a shorter amount of time (Gomez and Vannini 2016). Another reason why photo-elicitation helped to mediate the cultural distance between us was because I did not take for granted what the participants' photos were about. Giving them the opportunity to explain their visual choices, helped us to begin a dialogue that was not centered on preconceived notions of each other. The visual material had many layers of interpretation, and I saw that photos could be easily misunderstood or attributed unintended meanings. In this sense, photos required participants to give their own interpretation of the ICTs and CMCs, and I needed to engage with them to confirm our understandings. During this process, I noticed that participants were engaging in the photo-elicitation activity to achieve outcomes that were not planned within the research. Asking detailed explanations both about the pictures and the participants' intention became a necessity, as many times I could not infer my participants' picture choices. For instance, participants were taking photos of ICTs and the CMCs to document evidence of neglect or of changes they wished to see. This was in contrast with taking photographs that represented abstract concepts of ICTs, or the meanings they attach to the CMCs metaphorically. Figure 4 shows two pictures that were taken to show displeasure with the state of the CMCs and their surroundings. On the left, a photo of moldy walls, and on the right, is a picture of rubbish strewn about. These pictures communicated aspects of the CMCs that the participants did not like, and wanted fixed.

As such, the participants viewed CMCs in Mozambican communities as a prominent place that they wanted to feel proud of. They hoped that their photos could contribute ideas about how to make it a safer place, a role model for disease prevention, and a place for civic engagement. The benefit of the second phase of research was that it provided a forum for CMCs Directors to build on their situational awareness of ICT and the CMCs, and to generate ideas which we called actions for improvement. During the focus groups, CMC Directors had an opportunity to brainstorm ideas and to decide which ideas should be prioritized for each of the communities they were representing. At the end of the focus groups, each director selected one idea. The research team helped directors to implement each idea and gave a small budget of $\$ 1500$ USD per CMC.

Furthermore, when the CMC directors saw the meanings and values the participants gave to the CMCs, it was not an 


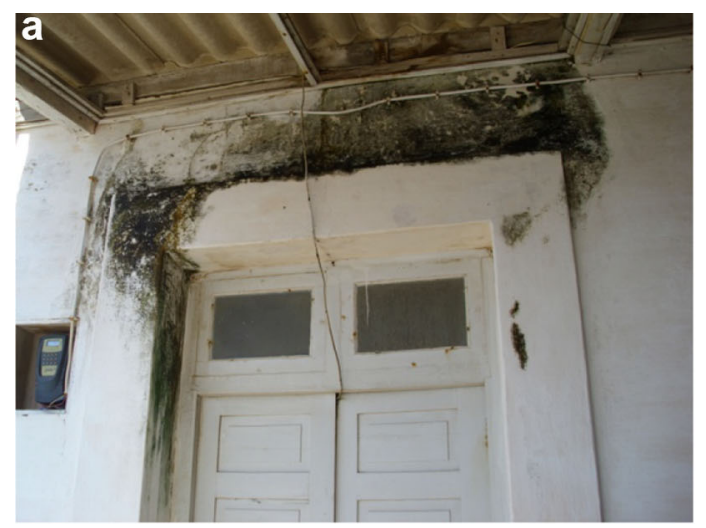

Fig. 4 Photos of CMC aspects that participants wanted changed

unmasking experience for directors as it was for the researchers. For instance, in response to the photo of rubbish (Fig. 4), a director said, "we always talk at the radio about the importance of hygiene to prevent the spread of diseases, they want the CMC to be clean because we have to set the example for the community, and we have to do what we predicate". Another director commenting on a picture pointing out the moldy walls as something to improve, explained how the look of the CMC environment was essential for a positive community experience with the initiative, because "beauty is important for the human being... beauty is a value that makes human beings what they are". The directors' cultural identities enabled them to grasp meanings and intentions of the photos more quickly, thus the focus group facilitated both participants and directors to establish a common understanding and to share it with the research team.

In contrast, a crucial aspect of the process was the way in which the photos reified community values in a way that supported concrete action and decision-making. For the directors, the photos helped to give a voice to the participants to decide what they wanted to do. Some of the directors chose to respond to the requests, whilst others were skeptical and unresponsive. Nevertheless, the photos provided a snapshot of the issues and recorded an instance of the improvement actions most needed or desired by community members. The actual outcomes of the planned improvements were investigated by David (2017), whilst I assisted only during the action-planning. For my research, photo-elicitation was a useful method to understand local meanings associated with perceptions of CMCs, as I was able to gauge details that would not have been clear to me otherwise, or that I could have easily overlooked. Associated interviews helped to give context to meanings and interpretations, which could not be inferred by researcher only through photos.

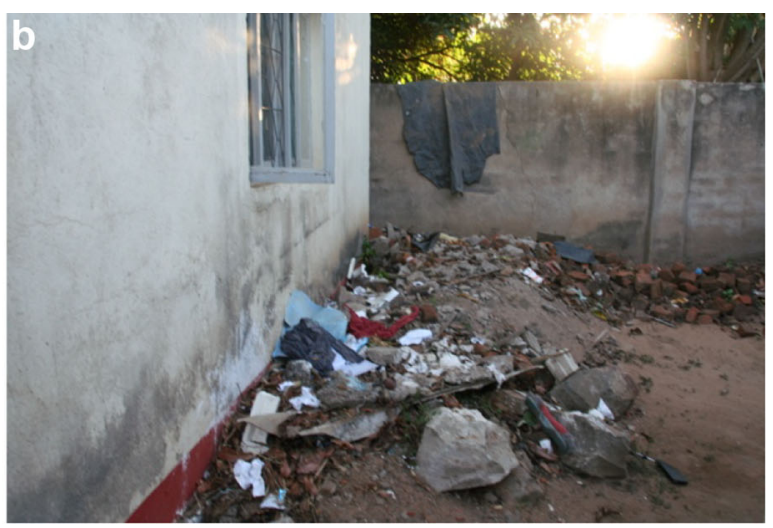

\section{Discussion}

This paper, which addresses the broad question of how to enable people to take control of ICT within their work and personal lives, has shown that, when visual methods are used to include participants in research processes, the conceptual virtues of ICT come more easily to the surface. Many other methods and techniques can lead to critical engagement with ICT, however, we synthesize findings across our case studies to suggest three main conclusions regarding the contributions of visual methods to this objective.

First, situational awareness of the role of ICT in context is necessary, but insufficient for critical ICT engagement. Our cases confirmed existing visual methods research in that underlying concepts and symbolism regarding ICT were successfully uncovered through both photographs and picture drawing. As Clark-Ibáñez (2016) has argued, pictures were beneficial for sparking discussion and gathering interpretations in a participatory fashion. There are countless examples of ways to involve participants in understanding ICT in context that directly improve the effectiveness of initiatives (Maunder et al. 2007; Kleine 2010; Heeks and Stanforth 2015). However, most initiatives are conceived by project managers, funders or researchers, which taints the focus of ICT. Encouraging participants to elucidate their own meanings of ICT is not generally a part of a pre-determined initiative, and which visual methods can support this process quickly and effectively. All cases demonstrated that the meanings researchers and participants attached to ICT were significantly different than pre-supposed. Participants also gained a sense of empowerment when their meanings and contributions derived value for their personal identities and community places. However, situational awareness was not sufficient for critical ICT engagement for two reasons. First, situational awareness helped participants to articulate meaning, but did not always suggest satisfaction with the 
status quo. For instance, Bentley's case demonstrated that participants were aware of the situated meanings of ICTs, but only came to question their practices through discussion. Second, Nemer and Vannini's cases highlighted that when critical engagement with ICT is viewed as a constructive process, it can lead to changes within social and organizational structures over time. Visual methods supported researchers and participants to understand ICT in context, but they also contributed evidence and enduring artifacts (such as the photo book in Nemer's case) that can be drawn upon for future change. Each of these reasons are expanded upon in the remaining two conclusions.

The second conclusion is that researchers are major players in developing reflexive ICT practice skills. Typically, participants' attitudes towards ICT were pragmatic and positively affirmative. Participants across the three cases were familiar with private companies and organizations directing how ICT is properly used. Participants were not accustomed to examining their own ICT agency prior to intervention. Nemer's case showed a dramatic change in the way participants thought about their own ICT practice, that would not likely have occurred without the experience of creating the photo book. Furthermore, each case study involved external researchers who needed to renegotiate their own cultural identities and how these influenced their own concepts and assumptions of ICT. There were therefore different levels of reflexive ICT practice occurring simultaneously. In research, discussions have centered on reflexivity from a researcher's perspective as reflecting on self, process, and positionality amidst the power relations and politics (Sultana 2007). However, we suggested that parochial functionalism and emancipatory logic tend to focus research too narrowly on specific goals and uses of ICT. The cultural identity lens puts forth the notion that cultural differences and issues are brought to the fore through practice and negotiation in participatory ICT4D research. Thus, we suggest that reflexive ICT practice involves examining one's role within the interaction between emancipatory objectives and situational awareness of ICT. For researchers, this requires openness and receptiveness to support participants to build on their own situated views and practices with ICT, as in Vannini's case when she noticed participants engaged in the research to present evidence rather than to build meaning. For participants, the concept of reflexivity may also be too abstract. Reflexivity is difficult for researchers (Rose 1997), so it should not be assumed that participants can change their ICT practice merely by reflecting on their power and position. Therefore, visual methods are an important tool for researchers to support participants to develop reflexive ICT practice skills, primarily through dialogue. Across all case studies, visual methods were illuminating to the participants, but participants needed guidance to question their visual representations, and to show them a different way of seeing or using ICT through discussion.

This brings us to our third conclusion, that critical engagement with ICT is a fundamental aspect to consider in processes of social and organizational change. An important finding that emerged through comparing cases relates to influencing social and organizational structures. All three cases had an intention to change structures through the design and use of ICT and related services. However, different levels of structural change were achieved. Vannini's case perhaps effected the most visible transformation because the participants' views were incorporated into concrete changes in the ways that $\mathrm{CMCs}$ directors chose to service their community. Whereas, Nemer's case demonstrated that working with visual methods to engage participants not only contributed to showing favela residents how to value ICT differently, but, through the artifact produced, also contributed to potentially changing upper-class citizen discrimination against the residents. The visual elements in these cases unlocked a communication channel that otherwise did not exist. In contrast, Bentley's case aimed to unlock this potential, but due to the time and organizational constraints faced, the modeling interviews were only a first nudge towards organizational change. Rich pictures helped participants to take notice of ICTs within their work practices, and to identify key issues to resolve. Yet, a coherent and longterm strategy for organizational change was needed to resolve these issues. As Dearden and Rizvi (2015) argue, participatory initiatives will always involve a set of compromises and trade-offs, and priorities will not likely be shared by all stakeholders. However, through participatory ICT4D research, within which researchers support participants to critically engage with ICT by developing an awareness of ICT, by reflexively changing their ICT practice, and by taking more power and control over ICT, individuals may be more likely to influence change.

\section{Conclusion}

A first major challenge in the current historical context is how to deal with pervasive structural inequality, which in many respects are deepened and magnified by ICT access and use patterns, particularly in the context of underserved communities in the Global South, or development organizations working to support them. The second challenge is to empower people to develop a critical consciousness of ICT, given that ICT is not neutral, and that people hold many diverse meanings and uses for ICT regardless of their intended purpose. We argued that parochial functionalist and emancipatory research orientations have both neglected to situate their practice within this wider historical 
context. In a state of profound transition, ICT4D scholars are perhaps unsure of where this is all going. The simplest and most equitable conclusion we suggested in this article, is to take critical engagement with ICT as the linchpin for meaningful growth in this area. As such, we suggested that there are three key aspects of critical ICT engagement: (1) increasing awareness of ICT in context, (2) developing reflexive ICT practice, and (3) increasing power and control over use or design of ICT. This article explored the use of visual methods to empower individuals and communities in these ways.

Our goal is to establish the relevance of emphasizing meanings and practices of ICT in participatory ICT4D, particularly in research and development practice that addresses underserved communities. Participatory researchers are perhaps traumatized by the constant battle to confront technological deterministic views in development, and may choose to deemphasize the role of ICT. However, we must recognize that ICT is increasingly intertwined and embedded in our individual and collective identities and environments. Research that embraces critical engagement with ICT will be important for understanding and facilitating responses to ubiquitous inequalities caused by ICT. To that end, this article shows that visual methods, either as a standalone initiative, or as part of a program of research, are a beneficial starting point. We encourage future research that tests our assumptions regarding critical engagement with ICT. Theoretical and methodological development utilizing a cultural identity lens may be beneficial for further exploration of the three proposed dimensions of critical ICT engagement in participatory research.

\begin{abstract}
Acknowledgements Bentley's research was kindly supported with grants from the ICT4D Centre, Royal Holloway, University of London, and a Slawson Award for Fieldwork, from the Royal Geographic Society (with IBG). We also wish to thank Amalia Sabiescu for her editorial guidance.
\end{abstract}

Open Access This article is distributed under the terms of the Creative Commons Attribution 4.0 International License (http:// creativecommons.org/licenses/by/4.0/), which permits unrestricted use, distribution, and reproduction in any medium, provided you give appropriate credit to the original author(s) and the source, provide a link to the Creative Commons license, and indicate if changes were made.

\section{References}

Balboa CM (2014) How successful transnational non-governmental organizations set themselves up for failure on the ground. World Dev 54:273-287

Bebbington A, Hickey S, Mitlin DC (2008) Can NGOs make a difference? The challenge of development alternatives. Zed Books, London
Bentley CM (2017) Bilateral donors and civil society organizations: technologies for learning and accountability. Dissertation, Royal Holloway, University of London

Bignante E (2010) The use of photo-elicitation in field research. Exploring Maasai representations and use of natural resources. doi:10.4000/echogeo.11622. http://echogeo.revues.org

Blaikie N (2010) Designing social research, 2nd edn. Polity, Cambridge

Brunello P (2015) Broken Premises: Towards an intercultural understanding of bilateral co-operation in ICT for education in Burundi. Dissertation, Royal Holloway, University of London

Buskens I, Webb A (eds) (2009) African women and ICTs: investigating technology, gender and empowerment. Zed Books, London

Checkland P (2000) Soft systems methodology: a thirty year retrospective. Syst Res Behav Sci 17:S11-S58. doi:10.1002/ 1099-1743(200011)17:1

Checkland P, Poulter J (2006) Learning for action: a short definitive account of soft systems methodology, and its use practitioners, teachers and students, 1st edn. Wiley, West Sussex

Chib A (2015) Research on the impact of the information society in the global south: an introduction to SIRCA. In: Chib A, May J, Barrantes R (eds) Impact of information society research in the global south. Springer, Singapore, pp 1-17

Clark-Ibáñez M (2016) Framing the social world with photoelicitation interviews. Am Behav Sci 47:1507-1527. doi:10. 1177/0002764204266236

Collier J, Collier M (1986) Visual anthropology. UNM Press, Albuquerque

Custódio L (2014) Book review: favela digital: the other side of technology by David Nemer. In: http://eprints.lse.ac.uk/60626/1/ Book\%20Review_\%20Favela\%20Digital_\%20The\%20Other\% 20Side\%20of\%20Technology\%20by\%20David\%20Nemer\%20_\% 20Favelas\%20at\%20LSE.pdf. Accessed 5 Jan 2017

David S (2017) Community multimedia centres in mozambique: exploring and experimenting co-design. Dissertation, Università della Svizzera italiana

Dearden A, Rizvi H (2015) ICT4D and participatory design. In: Mansell R, Ang PH (eds) The international encyclopedia of digital communication and society. Wiley, London

Dell N, Vaidyanathan V, Medhi I, Cutrell E (2012) Yours is better!: participant response bias in HCI. ACM Press, New York, p 1321

Digital Caribou (2016) Winners and losers in the global app economy. Caribou Digital Publishing, Farnham

Doerflinger J, Dearden A, Gross T (2013) A software development methodology for sustainable ICTD solutions. ACM, New York

Donner J, Escobari MX (2010) A review of evidence on mobile use by micro and small enterprises in developing countries. J Int Dev 22:641-658. doi:10.1002/jid.1717

Ebrahim A (2003) NGOs and organizational change: discourse, reporting, and learning. Cambridge University Press, Cambridge

Floridi L (2016) The fourth revolution: how the infosphere is reshaping human reality. Oxford University Press, Oxford

Freire P, Giroux HA (1985) The politics of education: culture, power and liberation. Bergin \& Garvey Publishers, Westport

Gender Links (2010) Gender Links wins prestigious award for its work with local government. In: https://genderlinks.org.za/programmeweb-menu/a-press-releases/gender-links-wins-prestigious-awardfor-its-work-with-local-government-2010-10-29/. Accessed 31 May 2017

Gender Links (2016) GL Sunrise campaign wins investing in the future award. In: http://genderlinks.org.za/news/gl-sunrise-campaignwins-investing-in-the-future-award/. Accessed 31 May 2017

Gomez R, Vannini S (2016) Notions of home and sense of belonging in the context of migration in a journey through participatory photography. EJISDC 71:1-46 
Hakken D, Maté P (2014) The culture question in participatory design. ACM, New York, pp 87-91

Hall S (1996) Introduction. In: Hall S, du Gay P (eds) Questions of cultural identity. SAGE, London, pp 1-17

Hall S (1997) Representation: cultural representations and signifying practices. SAGE, London

Heeks R (2002) Failure, success and improvisation of information systems projects in developing countries. Institute for Development Policy and Management, University of Manchester, Manchester

Heeks R (2014) ICT4D 2016: new priorities for ICT4D policy, practice and WSIS in a post-2015 world. Centre for Development Informatics, Institute for Development Policy and Management, SEED, Manchester

Heeks R, Stanforth C (2015) Technological change in developing countries: opening the black box of process using actor-network theory. Dev Stud Res 2:33-50. doi:10.1080/21665095.2015. 1026610

Holgate J, Keles J, Kumarappan L (2012) Visualizing "community": an experiment in participatory photography among Kurdish diasporic workers in London. Sociol Rev 60:312-332. doi:10. 1111/j.1467-954X.2012.02075.x

Hoque MR, Sorwar G (2015) ICT based e-government services for rural development: a study of union information and service center (UISC) in Bangladesh. Electron J Inf Syst Dev Ctries 71:1-19

Irani L, Vertesi J, Dourish P et al (2010) Postcolonial computing: a lens on design and development. ACM, New York, pp 1311-1320

Kleine D (2010) ICT4what?-using the choice framework to operationalise the capability approach to development. J Int Dev 22:674-692

Kleine D, Unwin T (2009) Technological revolution, evolution and new dependencies: what's new about ICT4D? Third World Q 30:1045-1067. doi:10.1080/01436590902959339

Kraemer KL, Dedrick J, Sharma P (2009) One laptop per child: vision vs. reality. Commun ACM 52:66-73

Kranzberg M (1986) Technology and history: "Kranzberg's laws". Technol Cult 27:544-560. doi:10.2307/3105385

Kwok JY-C, Ku H-B (2008) Making habitable space together with female Chinese immigrants to Hong Kong. Action Res 6:261-283. doi:10.1177/1476750308094131

Leonardi PM (2012) Materiality, sociomateriality, and socio-technical systems: what do these terms mean? How are they different? Do we need them? In: Leonardi PM, Nardi BA, Kallinikos J (eds) Materiality and organizing social interaction in a technological world. Oxford University Press, Oxford, pp 25-48

Lewis D, Kanji N (2009) Non-governmental organizations and development. Routledge, London

Lunch N, Lunch C (2006) Insights into participatory video: a handbook for the field. InsightShare, London

Madison DS (2011) Critical ethnography. SAGE, London

Maunder A, Marsden G, Gruijters D, Blake E (2007) Designing interactive systems for the developing world-reflections on usercentred design. IEEE

Mello D (2016) Leitura é hábito de $56 \%$ da população, indica pesquisa. http://agenciabrasil.ebc.com.br/cultura/noticia/201605/leitura-e-habito-de-56-da-populacao-indica-pesquisa. Accessed 31 May 2017

Merritt S, Stolterman E (2012) Cultural hybridity in participatory design. ACM, New York, pp 73-76

Morgan D (1996) Focus groups as qualitative research, second edition (qualitative research methods series 16), 2nd edn. SAGE, London

Mosse EL, Byrne E (2010) The role of identity in health information systems development: a case analysis from Mozambique. Inf Technol Dev 11:227-243. doi:10.1002/itdj.20014
Nemer D (2013) Favela digital: the other side of technology. Editora GSA, Vitoria

Nemer D (2015a) Online Favela: the use of social media by the marginalized in Brazil. Inf Technol Dev. doi:10.1080/02681102. 2015.1011598

Nemer D (2015b) Rethinking digital inequalities: the experience of the marginalized in community technology centers. Dissertation, Indiana University

Nemer D (2016) Rethinking social change: the promises of Web 2.0 for the marginalized. First Monday 21:59-68. doi:10.1016/j. bushor.2009.09.003

Nguyen TN, Braa J (2016) Scaffolding health information infrastructure's generativity by scaffolded gateways: the case of Vietnam. Electron J Inf Syst 75:1-22

Okon U (2014) ICT for rural community development: implementing the communicative ecology framework in the Niger Delta Region of Nigeria. Inf Technol Dev 21:297-321. doi:10.1080/ 02681102.2015.1007819

Orlikowski WJ (2000) Using technology and constituting structures: a practice lens for studying technology in organizations. Organ Sci 11:404-428

Pink S (2004) Visual methods. In: Seale C, Gobo G, Gubrium JF, Silverman D (eds) Qualitative research practice. SAGE, London, pp 361-376

Rega I, Vannini S, Fino E, Cantoni L (2013) Exploring the meanings of Community Multimedia Centers in mozambique: a social representation perspective. ITID 9:35-54

Rhodes SD, Hergenrather KC, Griffith D et al (2009) Sexual and alcohol risk behaviours of immigrant latino men in the southeastern USA. Cult Health Sex 11:17-34. doi:10.1080/ 13691050802488405

Roberts T (2016) Critical-Agency in ICT4D: a case study of Zambian women's use of participatory video technology to challenge gender inequality. Dissertation, University of London

Rose G (1997) Situating knowledges: positionality, reflexivities and other tactics. Prog Hum Geogr 21:305-320. doi:10.1191/ 030913297673302122

Rubin HJ, Rubin IS (2011) Qualitative interviewing: the art of hearing data, 2nd edn. SAGE, London

Sadowsky G (ed) (2012) Accelerating development using the web: empowering poor and marginalized populations. World Wide Web Foundation, San Francisco

Sahay S, Lewis J (2010) Strengthening Metis around routine health information systems in developing countries. Int Dev Int Dev 6:67-84

Sultana F (2007) Reflexivity, positionality and participatory ethics: negotiating fieldwork dilemmas in international research. ACME 6:374-385

Tacchi J, Watkins J, Keerthirathne K (2009) Participatory content creation: voice, communication, and development. Dev Pract 19:573-584

Tedre M, Sutinen E, Kähkönen E, Kommers P (2005) Ethnocomputing: iCT in cultural and social context. Commun ACM 49:126-130

Toyama K (2015) Geek heresy. PublicAffairs, New York

Vallauri U (2015) ICTs, participatory video and farmer-led agriculture extension services in Machakos District, Kenya. Dissertation, Royal Holloway University of London

van der Boor P, Oliveira P, Veloso F (2014) Users as innovators in developing countries: the global sources of innovation and diffusion in mobile banking services. Res Policy 43:1594-1607. doi:10.1016/j.respol.2014.05.003

van Reijswoud V (2009) Appropriate ICT as a tool to increase effectiveness in ICT4D: theoretical considerations and illustrating cases. Electron J Inf Syst Dev Ctries 38:1-18 
Van Rooy A (ed) (2009) Civil society and the aid industry (earthscan library collection: aid and development set). Earthscan Publications Ltd., London

van Zyl I (2014) Indigenous logics: anthropological reflections on participatory design in community informatics

Vannini S, Rega I, Sala S, Cantoni L (2015) Using photo-elicitation to explore social representations of Community Multimedia Centers in Mozambique. Electron J Inf Syst Dev Ctries 67:1-23

Wallace T, Chapman J (1999) The aid chain: coercion and commitment in development NGOs. ITDG Publishing, London

World Bank (2016) World Development Report 2016: digital dividends. World Bank Group, Washington, DC
Yefimova K, Neils M, Newell BC, Gomez R (2015) Fotohistorias: participatory photography as a methodology to elicit the life experiences of migrants. IEEE, Hawaii, pp 3672-3681

Young L, Barrett H (2001) Adapting visual methods: action research with Kampala street children. Area 33:141-152. doi:10.1111/ 1475-4762.00017

Zheng Y, Stahl BC (2011) Technology, capabilities and critical perspectives: what can critical theory contribute to Sen's capability approach? Ethics Inf Technol 13:69-80. doi:10. 1007/s10676-011-9264-8 